\title{
Optimal Decision-making for Green Supply Chain Based on Overconfidence under the Carbon Emission Constraint
}

\author{
Yunxia Zhao \\ School of Statistics Science, Shandong University of Finance and Economics, Jinan 250014, China
}

Corresponding Author Email: yunxiazhao@vip.126.com

https://doi.org/10.18280/jesa.520213

Received: 8 January 2019

Accepted: 15 March 2019

\section{Keywords:}

overconfidence, carbon emission, green supply chain, green preference

\begin{abstract}
In light of the combination of overconfident manufacturer - rational retailer - green-preferring consumers, this paper establishes a Stackelberg game model under the carbon emission constraint, obtains the optimal green and emission reduction strategy and optimal pricing strategy in case of decentralized decision-making using the backward induction method, and further analyzes the impacts of the manufacturers' overconfidence and the consumers' green preference on the optimal decision and profit of the supply chain. According to the results of the study, under certain conditions, the low-carbon supply chain will no longer be "lowcarbon" and the carbon tax policy will be ineffective; over-confident manufacturers will reduce the investment in carbon emission reduction while increasing the wholesale price of unit products; rational retailers may expand the market demands for products at the expense of some of its profit margins; the profits of the supply chain system and its members are all negatively correlated with the manufacturer's overconfidence level, but positively correlated with the consumers' green preference level. Finally, the model is proved to be effective through example analysis, showing that it can provide some reference for relevant supply chain enterprises when they are making decisions on emission reduction investment.
\end{abstract}

\section{INTRODUCTION}

Since the World Climate Conference was held in Copenhagen in December 2009, governments around the world have successively issued policies to reflect the 20122020 global emission reduction agreement, so as to jointly respond to climate changes. China also promised that, by the end of 2020, it will reduce the carbon emission per unit of GDP by more than $40 \%$ compared with that in 2005 . Nowadays, many cities in China are suffering from smog and sandstorms [1], which are bringing serious impacts on people's life quality and socio-economic development. Such environmental problems have caught wide attention from scholars, especially the global warming caused by the emission of greenhouse gases like carbon dioxide, which has now become a research focus.

In order to control carbon dioxide emissions, governments have actively implemented carbon emission reduction policies [2]. There are many ways to reduce carbon emissions, such as carbon cap, carbon tax policy and carbon trading policy. Comparatively speaking, the carbon tax policy is favoured by developed countries because of its low cost [3]. China is also actively promoting the implementation of the carbon tax policy. As the ecological environment deteriorates, people are paying more attention to the sustainable supply chain management, and consumers are also becoming more aware of the importance of environmental protection, and as a result, they have a stronger preference and are more willing to pay for low-carbon green products. Therefore, it is of great practical significance to study the optimal decision-making problem of green supply chain under the carbon tax policy.

As mentioned above, global warming has caused widespread concern in the international community, and green development has gradually become the common understanding for the whole world. Most of the existing literatures only consider the adjustment of production and pricing strategies by supply chain enterprises under the government's carbon tax policy constraint, but few considers carbon emission enterprises' investment in green emission reduction technology [4-6]. In fact, reducing the amount of carbon emission requires great technological and capital investment from carbon emission companies, which inevitably leads to an increase in costs. Therefore, it is an important decision-making problem for relevant enterprises as how to balance carbon emission and green technology investment and make the optimal strategy. Liu et al. [7] constructed a quadratic function to describe the relationship between greenness and cost. Xie [8] introduced government subsidies in the analysis of the greenness of and pricing decisions on green supply chain products. Drake et al. [9] studied the impacts of carbon tax, carbon cap and trading mechanism on enterprises' green technology choices and capacity decisions. Basiri and Heydari [10] studied the channel coordination problem of the two-tier green supply chain through a mathematical programming model. Jamali [11] established a two-channel competition model for green and non-green supply chains. Most of the existing research in this field assumes that decision makers are completely rational and does not consider their cognitive bias.

A large number of psychological studies show that individuals often tend to be overconfident in real economic life [12]. De Bondt et al. [13] verified the existence of overconfidence through empirical research. Ren and Croson [14] further confirmed that overconfidence is a possible reason 
for the "pull to centre" effect in newsvendor decision-making. $\mathrm{Li}$ et al. [15] demonstrated that overconfidence is one of the most consistent, powerful and widespread cognitive biases that influence decision making in the context of random outcomes. Liu et al. [16] studied the impact of dual overconfidence behaviour and demand updating on port service supply chain decision making. Xu et al. [17] explored the impact of the logistics service provider' overconfidence behaviour on the decision making for a supply chain with demand surge.

In summary, there are few studies considering green supply chain decision making under the carbon emission constraint, and most research assumes that decision makers are completely rational. This paper explores the optimal green emission reduction and Stackelberg pricing game strategies of supply chain enterprises subject to the carbon emission constraint under the joint effect of consumers' green preference and manufacturers' overconfidence. The main contributions of this paper are as follows: 1) it takes into account the impacts of both the consumers' green preference and the manufacturers' overconfidence on the optimal decision-making of the supply chain, and the existing literatures mostly consider only one of these two factors; 2) By comparing the carbon emission of a green supply chain with that of a non-green supply chain, it concludes that the lowcarbon supply chain will no longer be "low-carbon" under certain conditions, and that the carbon tax policy may become ineffective.

\section{PROBLEM DESCRIPTION AND PARAMETER HYPOTHESES}

In a secondary supply chain system, the manufacturer produces a type of green products, and the retailer buys them and sells them to the market. The retailer and the manufacturer constitute a Stackelberg game relationship with complete information, where the retailer is the leader and the manufacturer are the follower. The manufacturer has two decision variables - the wholesale price $w$ and the greenness $\theta$ of the product, while the retailer has only one decision variable - the profit margin per unit product $m$. The production cost per unit product $c$ of the manufacturer is an exogenous variable and $w>c$. In the entire supply chain, only the carbon emission generated by the manufacturer is considered. In order to produce green products, the manufacturer needs to invest part of its capital in production to obtain the green production technology. Obviously, the investment cost is positively correlated with the greenness of the product. To facilitate modelling and analysis, the following hypotheses are made:

Hypothesis 1 The market demand function is a linear function of the selling price, and consumers have a purchasing preference for green products, so it is assumed that the linear function of the market demand $q_{r}(p, \theta)$ is:

$$
q_{r}(p, \theta)=a-b p+\lambda \theta
$$

where, $a$ represents the product market capacity and $a>0 ; p$ is the retail price of the product and $p=w+m ; b$ is the consumers' price sensitivity and $b>0 ; \theta$ represents the greenness of the product; and $\lambda$ represents the consumers' sensitivity to green products, and $\lambda>0$ indicates that the increase in the greenness of the manufacturer's product can expand the market demand for the product.
Hypothesis 2 The manufacturer is the main body with carbon emission. This paper considers the constraint of the carbon tax policy on the carbon emission of enterprises. Suppose that the government imposes a carbon tax of $t$ per unit product that involves carbon emission on the manufacturer. In order to reduce carbon tax, the manufacturer will actively reduce the carbon emission during the production process, that is, it will invest in emission reduction technology to increase the greenness of the product. By reference to literature [18], it is assumed that

$$
H(\theta)=\frac{1}{2} \alpha \theta^{2}
$$

where, $\alpha$ represents the green emission reduction cost and $\alpha>$ $0 ; \theta$ is the greenness of the product and $\theta=\frac{e-e^{\prime}}{e}$, where $e$ represents the initial carbon emission per unit product, and $e^{\prime}=e(1-\theta)$ indicates the carbon emission per unit product after the manufacturer implements the invested green technology. Due to technical limitations, the manufacturer is unlikely to achieve zero carbon emission, so it is assumed that $0 \leq \theta<1$.

Hypothesis 3 In the eyes of a rational manufacturer, the market demand for the product is $q_{r}(p, \theta)$, but if the manufacturer is overconfident, it will overestimate the market demand for the green product. So in the eyes of an overconfident manufacturer, the market demand for the green product is

$$
q_{m}(p, \theta)=k(a-b p+\lambda \theta)
$$

where, $k$ is the manufacturer's overconfidence factor, and $k \geq$ 1 ; the greater the value of $k$, the more overconfident the manufacturer is.

\section{OPTIMAL DECISION MAKING FOR A RETAILER- LED GREEN SUPPLY CHAIN}

This section considers the master-slave Stackelberg game strategy for a fully rational retailer and an overconfident manufacturer in the decentralized decision-making model. Before the selling season, the retailer first determines the profit margin per unit product $m$. After knowing the retailer's decision, the manufacturer determines the greenness $\theta$ and the wholesale price $w$ of the product. Both sides of the supply chain aim to maximize their own profits. Their respective profit functions are:

$$
\begin{aligned}
& \pi_{r}(m)=m q_{r}(p, \theta)=m(a-b m-b w+\lambda \theta) \\
& \pi_{m}(w, \theta)=w q_{r}(p, \theta)-(c+t) q_{m}(p, \theta)-\frac{1}{2} \alpha \theta^{2}= \\
& {[w-(c k+t k)](a-b m-b w+\lambda \theta)-\frac{1}{2} \alpha \theta^{2}}
\end{aligned}
$$

Proposition 1 When the parameter satisfies $2 b \alpha-\lambda^{2}>0$, (i) the optimal profit margin of the rational retailer is $m^{*}=$ $\frac{a-b(c k+t k)}{2 b}$; and (ii) the optimal green emission reduction level of the overconfident manufacturer's product is $\theta^{*}=$ $\frac{\lambda[a-b(c k+t k)]}{2\left(2 b \alpha-\lambda^{2}\right)}$, and the optimal wholesale price is $w^{*}=$ $\frac{\alpha[a-b(c k+t k)]+2(c k+t k)\left(2 b \alpha-\lambda^{2}\right)}{2\left(2 b \alpha-\lambda^{2}\right)}$ 


$$
\begin{gathered}
\frac{\partial \pi_{\mathrm{m}}(\mathrm{w}, \theta)}{\partial \mathrm{w}}=(\mathrm{a}-\mathrm{bm}-\mathrm{bw}+\lambda \theta)-\mathrm{b}[\mathrm{w}-(\mathrm{ck}+\mathrm{tk})]=0 \\
\frac{\partial \pi_{\mathrm{m}}(\mathrm{w}, \theta)}{\partial \theta}=\lambda[\mathrm{w}-(\mathrm{ck}+\mathrm{tk})]=0
\end{gathered}
$$

Combine the above equations, and there are:

$$
\left\{\begin{array}{c}
\mathrm{w}=\frac{\alpha[\mathrm{a}-\mathrm{bm}+\mathrm{b}(\mathrm{ck}+\mathrm{tk})]-\lambda^{2}(\mathrm{ck}+\mathrm{tk})}{2 \mathrm{~b} \alpha-\lambda^{2}} \\
\theta=\frac{\lambda[\mathrm{a}-\mathrm{b}(\mathrm{ck}+\mathrm{tk}+\mathrm{m})]}{2 \mathrm{~b} \alpha-\lambda^{2}}
\end{array}\right.
$$

Since the Hessian matrix of $\pi_{\mathrm{m}}(\mathrm{w}, \theta)$ is:

$$
H(w, \theta)=\left[\begin{array}{ll}
\frac{\partial^{2} \pi_{m}(w, \theta)}{\partial w^{2}} & \frac{\partial^{2} \pi_{m}(w, \theta)}{\partial w \partial \theta} \\
\frac{\partial^{2} \pi_{m}(w, \theta)}{\partial w \partial \theta} & \frac{\partial^{2} \pi_{m}(w, \theta)}{\partial \theta^{2}}
\end{array}\right]=\left[\begin{array}{cc}
-2 b & \lambda \\
\lambda & -\alpha
\end{array}\right]
$$

The first-order principal minor is $\frac{\partial^{2} \pi_{m}(w, \theta)}{\partial w^{2}}=-2 b<0$. When $2 b \alpha-\lambda^{2}>0$, $\operatorname{det}[\mathrm{H}(\mathrm{w}, \theta)]>0$, so $\mathrm{H}(\mathrm{w}, \theta)$ is a negative definite matrix, and (7) is the only optimal solution for the manufacturer's profit.

Substitute (7) into (4), and there is:

$$
\pi_{\mathrm{r}}(\mathrm{m})=\frac{\mathrm{mb} \alpha[\mathrm{a}-\mathrm{bm}-\mathrm{b}(\mathrm{ck}+\mathrm{tk})]}{2 \mathrm{~b} \alpha-\lambda^{2}}
$$

Calculate the first and second derivatives of $\pi=\mathrm{r}(\mathrm{m})$ with respect to $m$, and there are:

$$
\begin{aligned}
& \frac{\mathrm{d} \pi_{\mathrm{r}}(\mathrm{m})}{\mathrm{dm}}=\frac{\mathrm{b} \alpha[\mathrm{a}-2 \mathrm{bm}-\mathrm{b}(\mathrm{ck}+\mathrm{tk})]}{2 \mathrm{~b} \alpha-\lambda^{2}} \\
& \frac{\mathrm{d}^{2} \pi_{\mathrm{r}}(\mathrm{m})}{\mathrm{dm}^{2}}=\frac{-2 \alpha \mathrm{b}^{2}}{2 \mathrm{~b} \alpha-\lambda^{2}}<0
\end{aligned}
$$

So $\pi_{r}(m)$ is a strictly concave function of $m$. Let $\frac{d \pi_{r}(m)}{d m}=$ 0 , that is, the retailer's optimal profit margin $m^{*}$ is:

$$
\mathrm{m}^{*}=\frac{\mathrm{a}-\mathrm{b}(\mathrm{ck}+\mathrm{tk})}{2 \mathrm{~b}}
$$

Substitute the value of $m^{*}$ into (7), and we have the equilibrium wholesale price and the optimal greenness of the overconfident manufacturer's product as follows:

$$
\left\{\begin{array}{c}
\mathrm{w}^{*}=\frac{\alpha[\mathrm{a}-\mathrm{b}(\mathrm{ck}+\mathrm{tk})]+2(\mathrm{ck}+\mathrm{tk})\left(2 \mathrm{~b} \alpha-\lambda^{2}\right)}{2\left(2 \mathrm{~b} \alpha-\lambda^{2}\right)} \\
\theta^{*}=\frac{\lambda[\mathrm{a}-\mathrm{b}(\mathrm{ck}+\mathrm{tk})]}{2\left(2 \mathrm{~b} \alpha-\lambda^{2}\right)}
\end{array}\right.
$$

Note: The green emission reduction cost considered in this paper is the cost of a new technology in which the manufacturer invests in a lump sum, so it is generally assumed that $\alpha$ has a large value [19], and accordingly the condition $2 b \alpha-\lambda^{2}>0$ in Proposition 1 normally holds.

Proposition 2 When the parameter satisfies $3 b \alpha-2 \lambda^{2}>0$, the manufacturer's optimal wholesale price increases with the increase of its overconfidence factor $k$, but the retailer's optimal profit margin and the manufacturer's green emission reduction investment decreases with the increase of the overconfidence factor $k$.

Proof: from (12) and (13), it can be known that:

$$
\frac{\mathrm{dm}^{*}}{\mathrm{dk}}=-\frac{\mathrm{t}+\mathrm{c}}{2}<0
$$

$$
\begin{aligned}
\frac{d w^{*}}{d k} & =\frac{\left(3 b \alpha-2 \lambda^{2}\right)(t+c)}{2\left(2 b \alpha-\lambda^{2}\right)}>0 \\
\frac{d \theta^{*}}{d k} & =\frac{-\lambda b(t+c)}{2\left(2 b \alpha-\lambda^{2}\right)}<0
\end{aligned}
$$

The overconfident manufacturer will overestimate the market demand brought about by the green emission reduction investment, but the retailer is completely rational. It will not order the excess products produced by the manufacturer due to overconfidence, so with the manufacture's overconfidence increasing, in order to avoid its loss and maximize its profit, the manufacturer will, on one hand, reduce its green emission reduction investment to reduce the risk of overproduction, and on the other hand, increase the wholesale price of the product to obtain more profit. After the wholesale price of the manufacturer increases, if the profit margin of the rational retailer does not change or increase, the retail price of the product will increase, which will lead to further shrinking of the market demand for the product, so the rational retailer may increase the market demand for the product at the expense of some of its profit margin so as to maximize its total profit.

Proposition 3 When the parameter satisfies $2 b \alpha-\lambda^{2}>0$ and the supply chain reaches the Stackelberg equilibrium: (i) the optimal retail price of the product is $p^{*}=$ $\frac{\alpha[a-b(c k+t k)]+2(c k+t k)\left(2 b \alpha-\lambda^{2}\right)}{2\left(2 b \alpha-\lambda^{2}\right)}+\frac{a-b(c k+t k)}{2 b}$; (ii) the maximum market demand for the product is $q_{r}^{*}(p, \theta)=\frac{b \alpha[a-b(c k+t k)]}{2\left(2 b \alpha-\lambda^{2}\right)}$.

Proof: Substitute (12) and (13) into the retail price of the product $p=w+m$, and there is:

$$
\mathrm{p}^{*}=\frac{\alpha[\mathrm{a}-\mathrm{b}(\mathrm{ck}+\mathrm{tk})]+2(\mathrm{ck}+\mathrm{tk})\left(2 \mathrm{~b} \alpha-\lambda^{2}\right)}{2\left(2 \mathrm{~b} \alpha-\lambda^{2}\right)}+\frac{\mathrm{a}-\mathrm{b}(\mathrm{ck}+\mathrm{tk})}{2 \mathrm{~b}}
$$

Further, from $q_{r}(p, \theta)=a-b p+\lambda \theta$, the optimal demand $q_{r}^{*}(p, \theta)$ for the product at equilibrium can be obtained as follows:

$$
\mathrm{q}_{\mathrm{r}}^{*}(\mathrm{p}, \theta)=\frac{\mathrm{b} \alpha[\mathrm{a}-\mathrm{b}(\mathrm{ck}+\mathrm{tk})]}{2\left(2 \mathrm{~b} \alpha-\lambda^{2}\right)}
$$

Proposition 4 When the parameter satisfies $2 b \alpha-\lambda^{2}>0$ and the supply chain reaches the Stackelberg equilibrium: (i) the maximum profit of the rational retailer is $\pi_{r}(m)=$ $\frac{\alpha[a-b(c k+t k)]^{2}}{4\left(2 b \alpha-\lambda^{2}\right)}$; (ii) the maximum profit of the overconfident manufacturer is $\pi_{m}(w, \theta)=\frac{\alpha[a-b(c k+t k)]^{2}}{8\left(2 b \alpha-\lambda^{2}\right)}$; and (iii) the maximum profit of the entire supply chain system is $\pi_{m r}(w, \theta, m)=\frac{3 \alpha[a-b(c k+t k)]^{2}}{8\left(2 b \alpha-\lambda^{2}\right)}$.

Proof: Substitute (12) and (13) into (4) and (5), respectively, and we can calculate the maximum profit of the rational retailer $\pi_{r}(m)$ and the maximum profit of the overconfident manufacturer $\pi_{m}(w, \theta)$ respectively as follows:

$$
\begin{aligned}
& \pi_{r}(m)=\frac{\alpha[a-b(c k+t k)]^{2}}{4\left(2 b \alpha-\lambda^{2}\right)} \\
& \pi_{m}(w, \theta)=\frac{\alpha[a-b(c k+t k)]^{2}}{8\left(2 b \alpha-\lambda^{2}\right)}
\end{aligned}
$$

Add the above two equations, and we obtain the maximum profit of the supply chain system:

$$
\pi_{m r}(w, \theta, m)=\frac{3 \alpha[a-b(c k+t k)]^{2}}{8\left(2 b \alpha-\lambda^{2}\right)}
$$


Below the constraint of the carbon tax policy on the manufacturer's green emission reduction is discussed. Suppose $E_{l}=e\left(1-\theta^{*}\right) k q_{r}^{*}(p, \theta)$, representing the carbon emission of the green supply chain, that $q_{r}^{0}(p)$ represents the order quantity of the rational retailer in the supply chain with no investment in green emission reduction and that $E_{0}=$ ek $q_{r}^{0}(p)$ indicates the carbon emission of the supply chain with no investment in green emission reduction, then $\Delta E=$ $E_{l}-E_{0}$ means the difference in carbon emission between the green supply chain and the non-green one.

Proposition 5 If the parameter satisfies $2 b \alpha-\lambda^{2}>0$, (i) when $\lambda>\sqrt{\frac{2 b^{2} \alpha t k}{a-b c k}}, q_{r}^{*}(p, \theta)>q_{r}^{0}(p) ;$ (ii) when $\theta^{*}<$ $\frac{q_{r}^{*}(p, \theta)-q_{r}^{0}(p)}{q_{r}^{*}(p, \theta)}, \Delta E>0$, where $q_{r}^{0}(p)=\frac{a-b c k}{4}$.

Proof: (i) In the non-green supply chain model, there is no need to consider the impact of the carbon tax policy and the investment cost of green emission reduction, so the profit function for the overconfident manufacturer is $\pi_{m}(w)=$ $(w-c k)(a-b m-b w)$. From $\frac{d \pi_{m}(w)}{d w}=0$, the optimal wholesale price $w^{0}$ can be obtained as follows:

$$
\mathrm{w}^{0}=\frac{\mathrm{a}-\mathrm{b}(\mathrm{m}-\mathrm{ck})}{2 \mathrm{~b}}
$$

The profit function for the retailer is $\pi_{r}(p)=m(a-b m-$ $b w)=m\left[a-b m-\frac{a-b(m-c k)}{2}\right]$. From $\frac{d \pi_{r}(p)}{d m}=0$, it can be seen that the optimal profit margin $m^{0}$ is:

$$
\mathrm{m}^{0}=\frac{\mathrm{a}-\mathrm{bck}}{2 \mathrm{~b}}
$$

Substitute (23) into (22), and the optimal wholesale price of the overconfident manufacturer is $w^{0}=\frac{a+3 b c k}{4 b}$. So the optimal order quantity for the rational retailer in the supply chain with no investment in green emission reduction is:

$$
\begin{gathered}
\mathrm{q}_{\mathrm{r}}^{0}(\mathrm{p})=\mathrm{a}-\mathrm{b}\left(\mathrm{w}^{0}+\mathrm{m}^{0}\right)=\frac{\mathrm{a}-\mathrm{bck}}{4} \\
\mathrm{q}_{\mathrm{r}}^{*}(\mathrm{p}, \theta)-\mathrm{q}_{\mathrm{r}}^{0}(\mathrm{p})=\frac{\mathrm{b} \alpha[\mathrm{a}-\mathrm{b}(\mathrm{ck}+\mathrm{tk})]}{2\left(2 \mathrm{~b} \alpha-\lambda^{2}\right)}-\frac{\mathrm{a}-\mathrm{bck}}{4} \\
=\frac{\lambda^{2}(\mathrm{a}-\mathrm{bck})-2 \mathrm{~b}^{2} \alpha \mathrm{tk}}{4\left(2 \mathrm{~b} \alpha-\lambda^{2}\right)}
\end{gathered}
$$

$2 \mathrm{~b} \alpha-\lambda^{2}>0$, so when $\lambda^{2}$ (a-bck) $-2 b^{2} \alpha$ tk $>0$, i.e. when $\lambda>$ $\sqrt{\frac{2 b^{2} \alpha t k}{a-b c k}}, q_{r}^{*}(p, \theta)>q_{r}^{0}(p)$.

(ii) Substitute $E_{l}=e\left(1-\theta^{*}\right) k q_{r}^{*}(p, \theta)$ and $E_{0}=$ ek $q_{r}^{*}(p)$ into $\Delta E=E_{l}-E_{0}$, and we have:

$$
\Delta \mathrm{E}=\mathrm{e}\left(1-\theta^{*}\right) \mathrm{kq}_{\mathrm{r}}^{*}(\mathrm{p}, \theta)-\operatorname{ek} \mathrm{q}_{\mathrm{r}}^{0}(\mathrm{p})
$$

So when $\theta^{*}<\frac{q_{r}^{*}(p, \theta)-q_{r}^{0}(p)}{q_{r}^{*}(p, \theta)}$, there is $\Delta E>0$.

The conclusion of proposition 5 (i) shows that when the green preference of consumers reaches a certain level, the market demand for products in the green supply chain will always be greater than that for the products in the non-green supply chain, which indicates that consumers' awareness of environmental protection expands the market demand for green products. The conclusion of proposition 5 (ii) shows that when the manufacturer's green emission reduction efficiency is below a certain level, the carbon emission of the green supply chain will be even greater than that of the non-green one, indicating that under certain conditions, the low-carbon supply chain will no longer be "low-carbon", and that the carbon tax policy may also be ineffective.

\section{EXAMPLE ANALYSIS}

This section uses the software Matlab to perform example analysis of the above model. It specifically discusses how the over-confident manufacturer chooses the optimal green emission reduction investment strategy under the carbon tax policy, and performs sensitivity analysis on parameters such as overconfidence factor and green preference coefficient to reveal the impacts of manufacturers' overconfidence behaviour and consumers' green preference behaviour on the optimal decision and profit of the supply chain. Further analysis shows that the manufacturer's green emission reduction efficiency is the key factor affecting its carbon emission. Through adjustment of the $k$ value, the conclusion is verified that the carbon emission of the green supply chain may also be greater than that of a non-green one. According to the definitions of parameters in the model and their relationships, the values of the parameters are assumed, as shown in Table 1. Based on the equilibrium solution and the values of the parameters in the model, the following values are obtained: $m^{*}=1.42, w^{*}=7.98, \theta^{*}=0.70, p^{*}=9.40$, $q_{r}^{*}(p, \theta)=8.14, \pi_{r}(m)=3.30, \pi_{m}(w, \theta)=1.65$ and $\pi_{m r}(w, \theta, m)=4.95$.

Table 1. Parameter setting

\begin{tabular}{cccccccc}
\hline Parameter & $\mathrm{a}$ & $\mathrm{b}$ & $\mathrm{c}$ & $\lambda$ & $\alpha$ & $\mathrm{t}$ & $\mathrm{k}$ \\
\hline Value & 100 & 10 & 6.5 & 3.5 & 10 & 0.01 & 1.1 \\
\hline
\end{tabular}

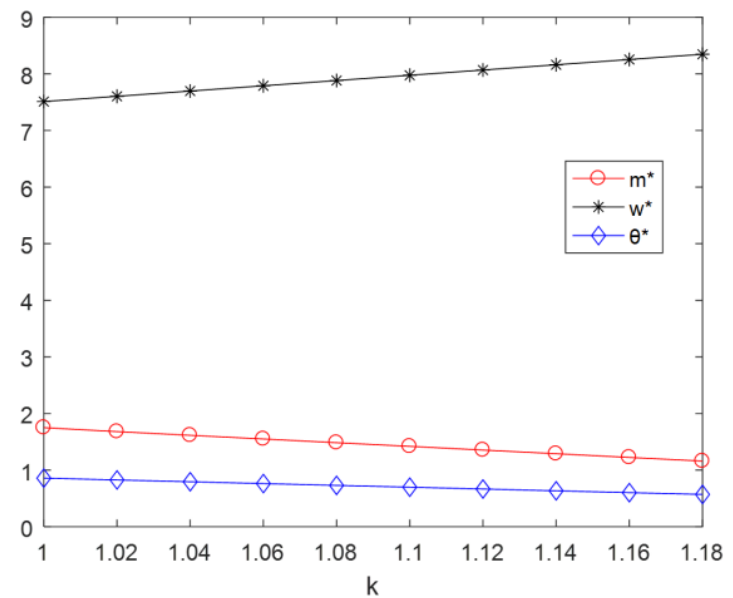

Figure 1. Impact of $\mathrm{k}$ on the optimal decision of the supply chain

Figure 1 and Figure 2 show the impacts of $k$ on the optimal decision and profit of the supply chain. Figure 1 shows that under the carbon tax policy, the optimal wholesale price of the manufacturer increases as the value of $k$ increases, while the optimal profit margin of the retailer and the green emission reduction investment of the manufacturer decrease as the value of $k$ increases, thus verifying the correctness of proposition 2 . As can be seen from Figure 2, as the value of $k$ increases, the profits of both the overconfident manufacturer and the rational retailer gradually decrease, so the profit of the entire supply 
chain also declines. This shows that the overconfident manufacturer overestimates the market demand, and such cognitive bias makes the decision making of the entire supply chain deviate from the optimal one, which leads to the reduction of the supply chain profit. It indicates that in a green supply chain led by the retailer under the carbon tax policy, it is particularly important to pay attention to the negative impact of the manufacturer's overconfidence on the green supply chain.

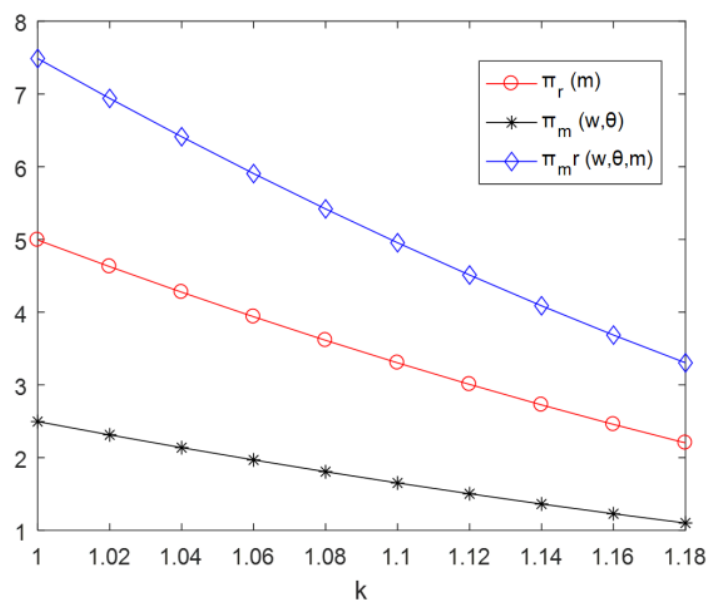

Figure 2. Impact of $\mathrm{k}$ on the profit of the supply chain

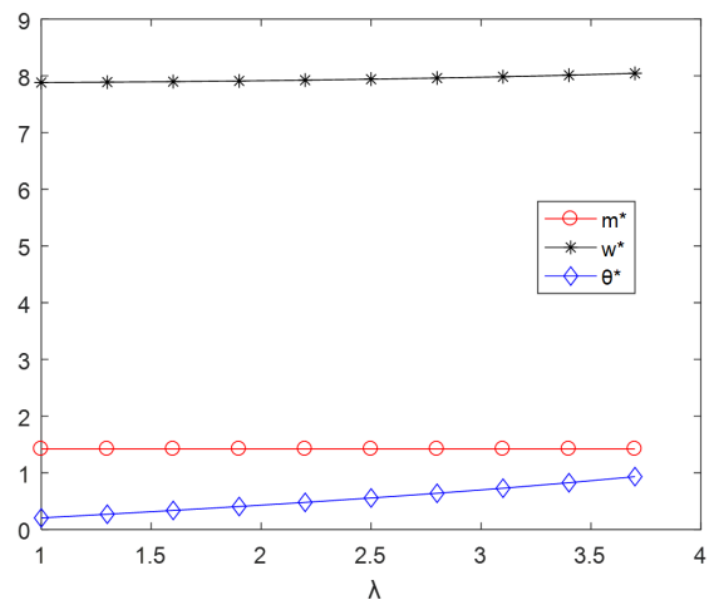

Figure 3. Impact of $\lambda$ on the optimal decision of the supply chain

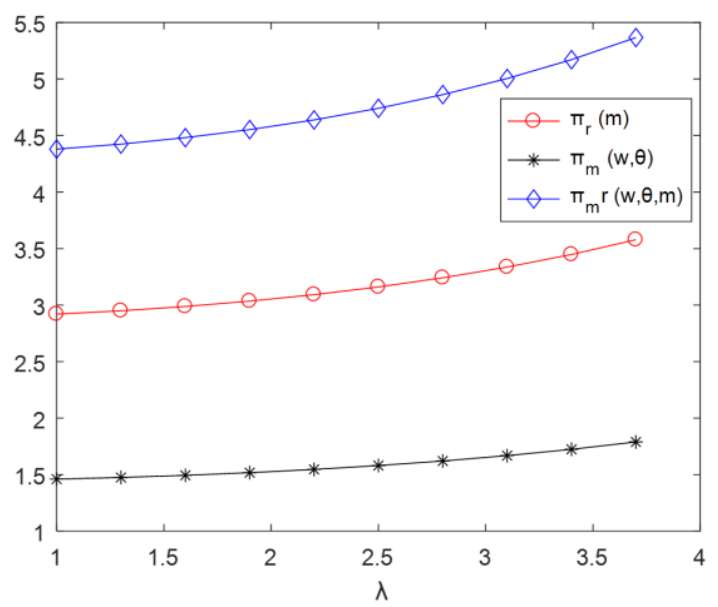

Figure 4. Impact of $\lambda$ on the profit of the supply chain
Figure 3 and Figure 4 show the impacts of $\lambda$ on the optimal decision and profit of the supply chain. Figure 3 shows that the optimal wholesale price and the green emission reduction investment of the overconfident manufacturer increase with the increase of the $\lambda$ value. Judging from the trend of the curve, the green emission reduction investment is more sensitive to the changes in the green preference of consumers, while the optimal profit margin of the retailer is not affected by the green preference of consumers. As can be seen from Figure 4, as consumers' green preference increases, the profits of the manufacturer, the retailers and the entire supply chain all increase. The reason is that the increase in the consumer's green preference can stimulate the expansion of product market demand, so that the entire supply chain system can benefit from it.

Figure 5 shows that when the initial carbon emission per unit product is $e=2$, under certain conditions, the market demand for the product in the green supply chain under the carbon tax policy is always greater than that in the non-green one; at the same time, when the manufacturer's overconfidence is low, the carbon emission of the green supply chain is smaller than that of the non-green one, but as the value of $k$ increases, the carbon emission of the green supply chain also increases, and when $\mathrm{k}=1.5$, the carbon emission of the green supply chain already exceeds that of the non-green one, which indicates that the green supply chain will no longer be "low-carbon", thus verifying proposition 5.

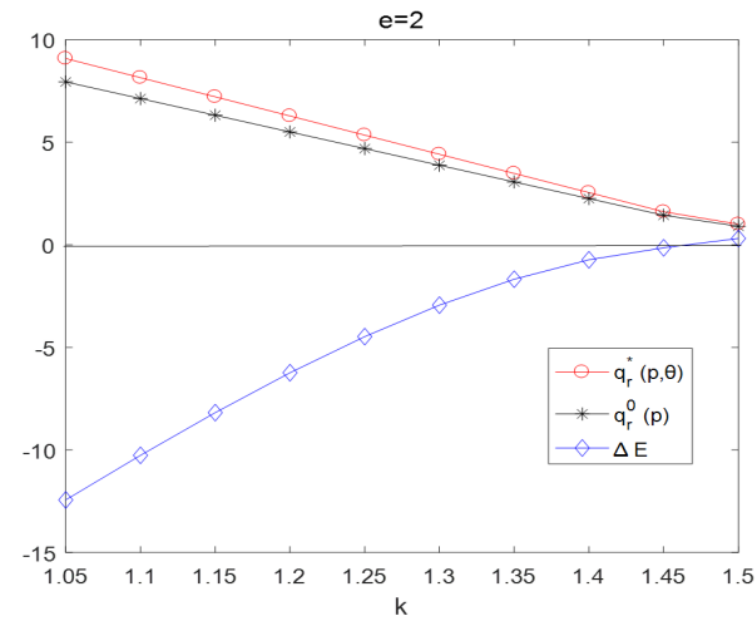

Figure 5. Green supply chain vs. non-green one in terms of market demand and carbon emission

\section{CONCLUSION}

In light of the combination of overconfident manufacturer rational retailer - green-preferring consumers, this paper establishes a Stackelberg game model under the carbon emission constraint, and discusses the optimal emission reduction investment and pricing strategies for a supply chain under the carbon tax policy. The results show that: 1) under certain conditions, the optimal wholesale price of the overconfident manufacturer is positively correlated with its level of overconfidence, but the optimal profit margin of the rational retailer and the emission reduction investment of the manufacturer are negatively correlated with the level of overconfidence; 2 ) the profits of the manufacturer, the retailer and entire supply chain decline as the manufacturer's overconfidence increases, but increase as the consumers' 
green preference increases; 3) under special conditions, the carbon emission of a green supply chain may be greater than that of a non-green one, and in this case, the carbon tax policy is ineffective.

There is still a lot of room for further research on this subject. Potential topics include the coordination of the green supply chain with carbon emission taken into account; the optimal decision-making problem for the supply chain when the retailer is also involved in green emission reduction; the circumstance when the manufacturer's overconfidence is asymmetric information.

\section{ACKNOWLEDGMENTS}

This research was supported by the Overseas Training Program for Excellent Young Teachers of Shandong University of Finance and Economics, the National Social Science Fund of China (No.18BJY205) and Shandong Provincial Social Science Planning Research Project (No.19CGLJ13).

\section{REFERENCES}

[1] Du, S., Hu, L., Song, M. (2016). Production optimization considering environmental performance and preference in the cap-and-trade system. Journal of Cleaner Production, 112(20): $1600-1607$.

https://doi.org/10.1016/j.jclepro.2014.08.086

[2] Barrieu, P., Fehr, M. (2014). Market-consistent modeling for cap-and-trade schemes and application to option pricing. Operations Research, 62(2): 234-249.

[3] Kuo, T.C., Hong, I.H., Lin, S.C. (2016). Do carbon taxes work? Analysis of government policies and enterprise strategies in equilibrium. Journal of Cleaner Production, 139(20): 337-346. https://doi.org/10.1287/opre.2013.1242

[4] Liu, B., Holmbom, M., Segerstedt, A., Chen, W.D. (2015). Effects of carbon emission regulations on remanufacturing decisions with limited information of demand distribution. International Journal of Production Research, 53(2): 532-548. https://doi.org/10.1080/00207543.2014.957875

[5] Ma, X., Ho, W., Ji, P., Talluri, S. (2018). Coordinated pricing analysis with the carbon tax scheme in a supply chain. Decision Sciences, 49(5): 863-900. https://doi.org/10.1111/deci.12297

[6] Miao, Z., Mao, H., Fu, K., Wang, Y. (2018). Remanufacturing with trade-ins under carbon regulations. Computers \& Operations Research, 89: 253-268. https://doi.org/10.1016/j.cor.2016.03.014

[7] Liu, Z.L., Anderson, T.D., Cruz, J.M. (2012). Consumer environmental awareness and competition in two-stage supply chains. European Journal of Operational Research,
218(3):

$602-613$

https://doi.org/10.1016/j.ejor.2011.11.027

[8] Xie, G. (2015). Modeling decision processes of a green supply chain with regulation on energy saving level. Computers \& Operations Research, 54: 266-273. https://doi.org/10.1016/j.cor.2013.11.020

[9] Drake, D.F., Kleindorfer, P.R., Van Wassenhove, L.N. (2016). Technology choice and capacity portfolios under emissions regulation. Production and Operations Management, 25(6): 1006-1025. https://doi.org/10.1111/poms.12523

[10] Basiri, Z., Heydari, J. (2017). A mathematical model for green supply chain coordination with substitutable products. Journal of Cleaner Production, 145: 232-249. https://doi.org/10.1016/j.jclepro.2017.01.060

[11] Jamali, M.B., Rasti-Barzoki, M. (2018). A game theoretic approach for green and non-green product pricing in chain-to-chain competitive sustainable and regular dual-channel supply chains. Journal of Cleaner Production, 170: 1029-1043. https://doi.org/10.1016/j.jclepro.2017.09.181

[12] Li, C., Zhou, Y., Chen, W., Li, J.C. (2014). Joint decision-making on order quantity and advertising expenditures for overconfident retailers. Journal of University of Sciences and Technology of China, 44(6): 523-530. https://doi.org/10.3969/j.issn.02532778.2014.06.012

[13] De Bondt, W.F.M., Thaler, R.H. (1990). Do security analysts overreact? The American Economic Review, 80(2): 52-57. https://doi.org/10.2307/2006542

[14] Ren, Y., Croson, R. (2013). Overconfidence in newsvendor orders: An experimental study. Management Science, 59(11): 2502-2517. https://doi.org/10.1287/mnsc.2013.1715

[15] Li, M., Petruzzi, N.C., Zhang, J. (2016). Overconfident competing newsvendors. Management Science, 63(8): 2637-2646. https://doi.org/10.1287/mnsc.2016.2469

[16] Liu, W., Shen, X., Wang, D. (2018). The impacts of dual overconfidence behavior and demand updating on the decisions of port service supply chain: A real case study from China. Annals of Operations Research, 1-40.

[17] Xu, L., Shi, X., Du, P., Govindan, K., Zhang, Z.C. (2019). Optimization on pricing and overconfidence problem in a duopolistic supply chain. Computers \& Operations Research, 101: 162-172. https://doi.org/10.1016/j.cor.2018.04.003

[18] Hong, Z., Dai, W., Lu, H., Yang, C.C. (2018). Optimal configuration of a green product supply chain with guaranteed service time and emission constraints. European Journal of Operational Research, 266(2): 663677. https://doi.org/10.1016/j.ejor.2017.09.046

[19] Wang, Q., Zhao, D., He, L. (2016). Contracting emission reduction for supply chains considering market lowcarbon preference. Journal of Cleaner Production, 120: 72-84. https://doi.org/10.1016/j.jclepro.2015.11.049 